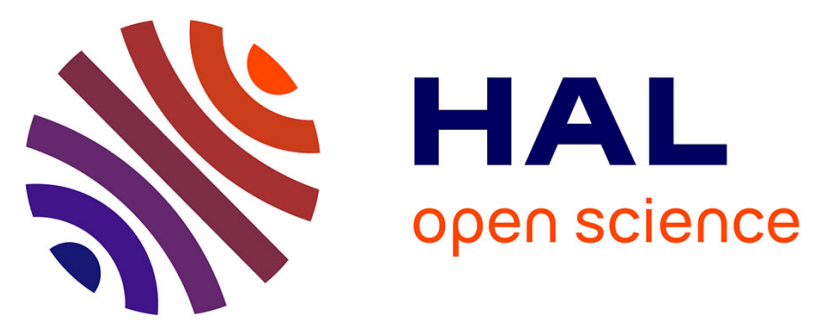

\title{
EXPERIMENTAL AND NUMERICAL INVESTIGATION OF POWDER VAPORIZATION UNDER THERMAL PLASMA CONDITIONS
}

Michel Vardelle, Armelle Vardelle, Pierre Fauchais, C. Trassy, P. Proulx

\section{- To cite this version:}

Michel Vardelle, Armelle Vardelle, Pierre Fauchais, C. Trassy, P. Proulx. EXPERIMENTAL AND NUMERICAL INVESTIGATION OF POWDER VAPORIZATION UNDER THERMAL PLASMA CONDITIONS. Journal de Physique Colloques, 1990, 51 (C5), pp.C5-171-C5-180. 10.1051/jphyscol:1990521. jpa-00230828

\section{HAL Id: jpa-00230828 https://hal.science/jpa-00230828}

Submitted on 1 Jan 1990

HAL is a multi-disciplinary open access archive for the deposit and dissemination of scientific research documents, whether they are published or not. The documents may come from teaching and research institutions in France or abroad, or from public or private research centers.
L'archive ouverte pluridisciplinaire HAL, est destinée au dépôt et à la diffusion de documents scientifiques de niveau recherche, publiés ou non, émanant des établissements d'enseignement et de recherche français ou étrangers, des laboratoires publics ou privés. 
COLLOQUE DE PHYSIQUE

Colloque C5, supplément au $\mathrm{n}^{\circ} 18$, Tome 51, 15 septembre 1990

EXPERIMENTAL AND NUMERICAL INVESTIGATION OF POWDER VAPORIZATION UNDER THERMAL PLASMA CONDITIONS

\author{
M. VARDELle, A. VARDELLE, P. FAuchais, C. TRASSY* and P. PROULX* * \\ University of Limoges, Laboratoire Ceramiques Nouvelies, URA 320,87060 \\ limoges Cedex, France \\ "INSA Lyon, Equipe "Spectrométrie des Plasmas", 69000 Lyon, France \\ * University of Sherbrooke Canada, Laboratoire de Génie Chimique, \\ sherbrooke, Canada
}

\title{
RESUME
}

Cet article présente une étude experimentale , par spectroscopie d'émission , de l'évaporation d'un grain isolé traité dans un jet de plasma d'arc.La température dans le nuage de vapeur qui se developpe autour du grain est determinée à partir du rapport d'intensité de 2 raies mesurées simultanement.

Le rayon du nuage de vapeur est déduit de la mesure de la vitesse des grains au même point de mesure par anémometrie laser et la concentration des atomes métalliques est calculée a partir du profil d'intensité d'une raie en supposant connue la température. Une étude numérique menée en parallèle de l'étude experimentale permet de prédire le chauffage et l'évaporation d'une particule isolée (sphérique) immergée dans un plasma infini au repos. Les résultats présentés concernent des grains de fer traités dans un jet de plasma argon-hydrogène.

\section{ABSTRACT}

For a basic understanding of the interaction of thermal plasmas with powders, a technique based on emission spectroscopy to investigate the vapour cloud surrounding a single particulate has been developed. The temperature within this "diffusion zone" is determined by the intensity ratio of two lines simultaneously measured. Its radius is deduced from the measurement of particulate velocity by laser doppler anemometry and the vapour concentration is calculated from the line intensity profile, once temperature is known. A specific computer algorithm of data acquisition and signal treatement allows systematic measurements.parallel to the experimental study, a model has been developed to predict the heating and the vaporization of a single particulate (assumed to be spherical) immersed in an infinite stagnant plasma. In a first approximation, thermodynamical equilibrium at the particulate surface is assumed.Results on iron particulates injected in an argon - hydrogen dc plasma jets are presented.

\section{I - INTRODUCTION}

Thermal plasma arc systems are being applied to a wide variety of powder processing including plasma spraying, powder densification, extractive metallurgy and industrial waste treatment $/ 1 /$.

The control and the optimization of the thermal plasma reactors which are, in general, highly heterogeneous systems require an understanding of the interaction of particulate matter with plasma flows.

In such flows with temperatures of the order of $10000 \mathrm{k}$, the heating rate of the injected particulates is very high. And these particulates can evaporate after a few millimeters of trajectory /2/ depending on particulate and plasma properties.

When vaporization occurs, mass transfer from the particulate surface towards the plasma gas reduces the effective heat transfer: the enthalpy directed to the surface is used to provide the latent heat of vaporization and to heat the vapor within the boundary layer. The vapor diffusion modifies the plasma gas composition and so its transport properties.

Although a fair amount of experimental work has been conducted on particulates trajectory, velocity and surface temperature distributions in dc plasma jets, little fundamental research has been done in the area of studying particulate vaporization. 
In this paper a study of the evaporation of iron particulates in argon hydrogen dc plasma jet is presented for low particulate loading rates.

\section{II - PRINCIPLE OF THE MEASUREMENTS AND EXPERIMENTAL SET UP}

The plasma system is a conventional spraying plasma torch with radial injection of powder at the nozzle exit with an injector of 1.6 mm internal diameter.

The working conditions of the torch are the following:



The investigated powder is iron. The particulates, whose diameters range from 22 to $44 \mu \mathrm{m}$, are injected into the plasma flow $2 \mathrm{~mm}$ upstream of the nozzle exit. The powder mass flow rate is lower than $200 \mathrm{~g} / \mathrm{h}$.

The used techniques to characterize evaporation and/or vaporization are absorption and emission spectroscopy.

The experimental set up for absorption spectroscopy measurement has been described in details elsewhere /3/.

The absorption technique enables to determine the population density of ground state of iron atoms or ions issued from particulate vaporization. This density is deduced from the absorption coefficient of the plasma determined by measuring the ratio of the flux Io of a source at the considered wavelength $\lambda$ to the transmitted flux it through the line of sight. In the investigated zone of plasma flow, the line broadening is mainly due to doppler effect. To calculate the population density and the line broadening, the temperature of the gas must be known. Thus the evolution of the plasma temperature along the torch axis is determined from the absolute emission coefficient of argon line ArI $727.2 \mathrm{~nm}$ assuming pressure and composition versus temperature are known. In such measurements, the air pumped in the plasma jet has been neglected according to the calculations of Roumilhac et al /4/ showing the error done on the temperature is below 5\% for temperatures higher than $7000 \mathrm{~K}$. In the range $6000-2000 \mathrm{~K}$, these measurements are completed by a few points corresponding to the melting points of refractory materials such as pure alumina and tungsten. Below $2000 \mathrm{~K}$ temperatures were measured using chromel - alumel thermocouples /2/. Both the thermocouple and melting point temperature measurements were corrected for conduction along the stem of the probe and for radiation losses. The temperature evolution of the investigated flow is given in figure 1 .

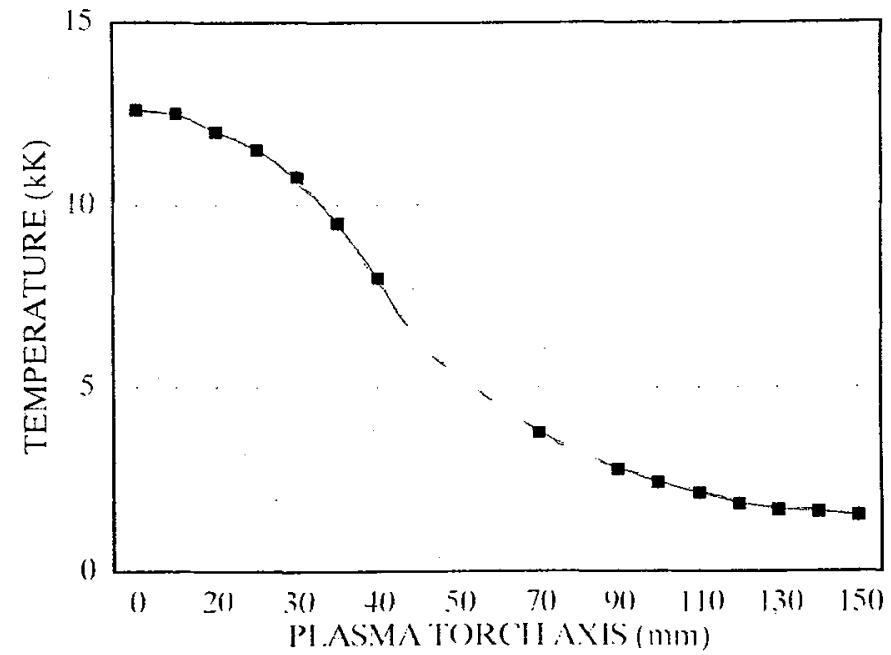

Figure 1: Gas temperature evolution along plasma torch axis. 
Measurements are performed along the mean trajectory of the particulates 13/. The absorption length is determined from the enlargement at mid-height of the radial distributions Io/It along this trajectory. For example in our experimental conditions, the absorption length is equal to $7 \mathrm{~mm}$ at $50 \mathrm{~mm}$ from the torch exit and $15 \mathrm{~mm}$ at $100 \mathrm{~mm}$.

The lines used in this study are the following $/ 5 /$ :

for FeI

for FeII $3906.48 \&$ $4287.4 \AA$

The emission spectroscopy technique allows determination of the metallic vapor concentration around a single particulate in flight.

The experimental set up shown in figure 2 has been adapted to study, at the same time, two lines of excited iron atoms:

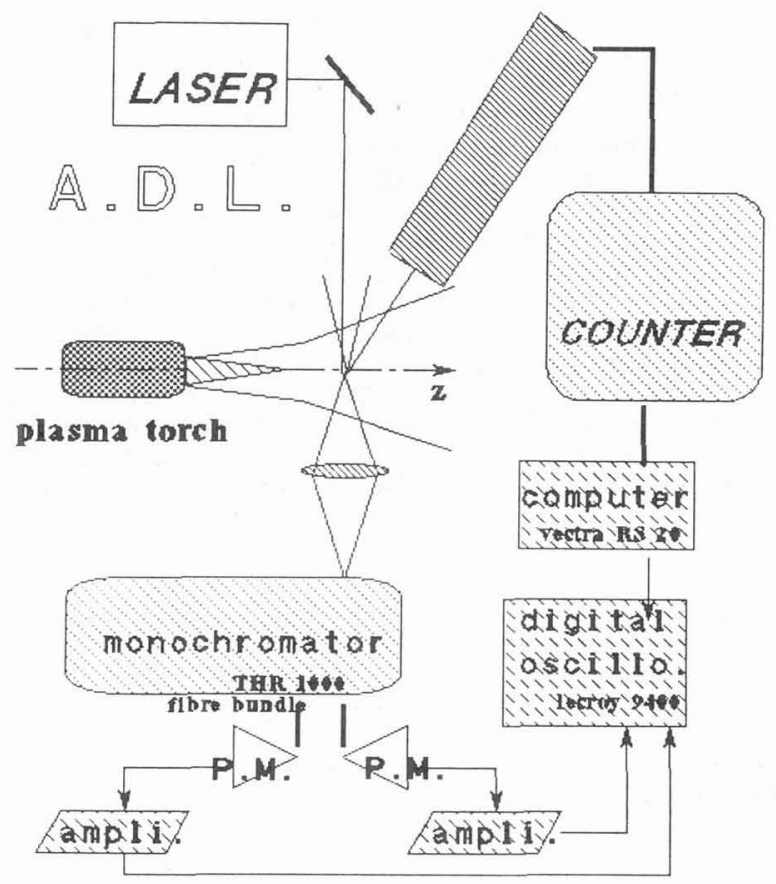

Figure 2: Schematic of the experimental set up used for emission spectroscopy and LDA measurements.

Details of this set up and the experimental procedure have been given in reference $13 /$. Therefore, the principle of measurements is only briefly recalled dwelling on last improvements brought to the technique.

The image of the measuring volume is made on the entrance slit of a JY HR 1000 monochromator with a magnification of two. The light pulses received by the monochromator when a particulate is passing through the observation zone are simultaneously detected by two optical fibers $(200 \mu \mathrm{m}$ in diameter). The focal field in the plasma flow corresponds approximatively to a cylinder whose diameter is equal to $100 \mathrm{um}$ and length to $15 \mathrm{~mm}$. A synchronisation detector set on an axis perpendicular to the line of sight enables to restrict the length of this cylinder to $1 \mathrm{~mm}$. The signals are processed by an oscilloscope which digitalizes the pulses with a sampling rate of 100 MHz. The data transferred to a HP RS 20 computer are processed using a specifically developed algorithm whose main operations are the following: 
- regrouping of points for each signal (each one being made up of 5000 points)

- locating of symmetry axis

- smoothing of the averaged signal

- Abel's inversion.

At present, only symmetric signals are processed (the selection is carried out by form recognition) to perform Abel's inversion.

These operations are carried out for the two signals simultaneously recorded and the temperature is determined from the ratio of the emission coefficients of the two lines (this ratio does'nt depend on the iron atom density but only on excitation temperature).

The FeI lines choosen for this study are the following /5/:

$\lambda_{1}=3705.6 \AA$

$\lambda_{2}=3758.2 \AA$

The why of the choice of these lines has been explained in reference $/ 6 /$.

The measurement of the particulate velocity by laser doppler anemometry /2/ enables to change the temporal evolution of the temperature into a spatial one, assuming that the velocity of particulate and its vapor cloud are identical: in this case the signals are almost symmetrical. This assumption is verified for distances higher than $45 \mathrm{~mm}$ from the powder injection port, whereas at the beginning of particulate trajectory, the plasma velocity is by far much higher than that of the particulates.

The iron atoms concentration in the vapor cloud is calculated from the line intensity profile once temperature evolution and cloud radius are known. To obtain absolute values for the integral intensities of spectral lines, the radiation of the investigated source is compared to that of a tungsten ribbon lamp with quartz window. This comparison is made under strictly identical conditions using the same optical elements, equal apertures... The population density $\mathrm{Nu}$ of the excited level $\mathrm{u}$ is related to the line emission coefficient $\varepsilon$ ul for the transition $u \rightarrow l$ by the well known equation $/ 7 /$ :

$$
\mathrm{Nu}=\frac{4 \pi}{\mathrm{Aul}} \frac{\lambda_{\mathrm{ul}}}{\mathrm{hc}} \varepsilon \mathrm{ul}
$$

where Aul denotes the transition probability upon the emission of radiation of wavelength $\lambda$ ul.

Assuming a Boltzmann distribution, the population density of fundamental state $\mathrm{N}$ is obtained by:

$$
N=\frac{N u \cdot Q}{g_{u} \exp (-E u / k T)}
$$

where $g_{u}$ is the statistical weight of the upper level, $Q$ the partition function and Eu the excitation energy of the upper level.

III - EXPERTMENTAL RESULTS

III - 1. Measurement of iron atom and ion concentration within the plasma flow by absorption spectroscopy.

The evolution of the concentration of iron atoms and ions is shown in figure 3. Each dot in this figure corresponds to a spatial and temporal average contrary to results presented in $\$ 3.2$. 


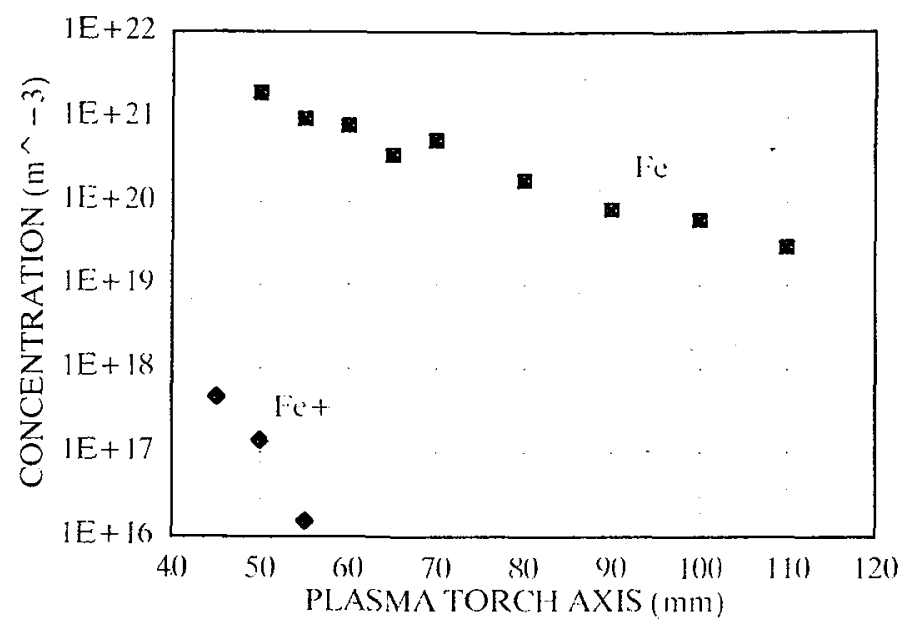

Figure 3: Iron atom and ion concentration along plasma torch axis.

Measurements were performed from $45 \mathrm{~mm}$ upstream of the nozzle exit. Below this distance, iron concentration is too high compared to the power level of the used standard source. In the investigated zone, the ion concentration is lower by three orders of magnitude than the atom one. Beyond $55 \mathrm{~mm}$, ion density is not even measurable.

The iron atom concentration regularly decreases from $3.10^{21} \mathrm{~m}^{-3}$ at $45 \mathrm{~mm}$ to $4.10^{19} \mathrm{~m}^{-3}$ at $110 \mathrm{~mm}$.

III - 2. study of the temperature and iron atom concentration around a single particulate.

The previous experiments have shown that the density of iron ions is low in the measuring zone so for measurements by emission spectroscopy only atomic spectral lines have been considered.

To determine the radius of the vapour cloud surrounding a single particulate, the velocity of the solid particulate has to be measured (see $\$$ 2). Results obtained by LDA on iron particulates are given in figure 4 a.

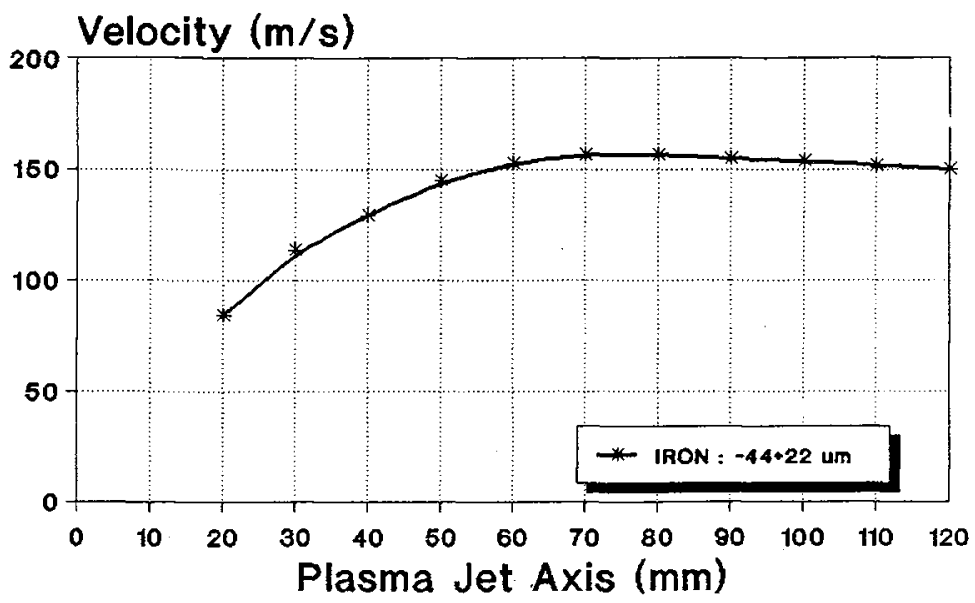

Figure $4 \mathrm{a}$ : Evolution of particulate velocity along the mean trajectory. Owing to the density of iron material $\left(7860 \mathrm{~kg} / \mathrm{m}^{3}\right)$, the axial particulate velocity is nearly constant from 60 to $120 \mathrm{~mm}$ from the injection point. 
Figure 4b gives the radial evolution of the velocity of the particulates as well as the corresponding R.M.S. This figure shows the importance to follow the vapor cloud at a precise location in the jet.

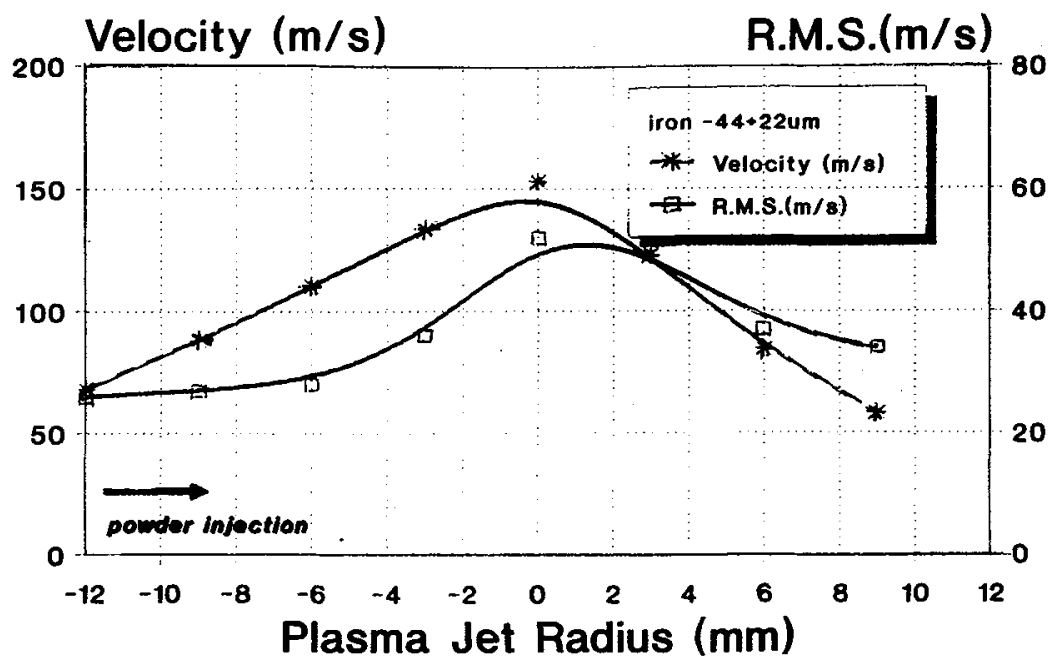

Figure 4b: Evolution of particulate velocity along the mean trajectory. ( RMS is the particulate velocity root mean square)

The main results of the investigation of the vapor cloud surrounding a particulate by emission spectroscopy are given in figures 5,6 and 7 .

In figure 5 is shown the evolution of the temperature along the vapor cloud radius at different distances from the injection point (each curve corresponds to the average calculated on ten signals). This temperature decreases drastically from 40 to $50 \mathrm{~mm}$, the difference between the temperatures measured at these distances being in the order of $1500 \mathrm{~K}, 40 \mathrm{~mm}$ corresponding to the limit of the plasma core and $50 \mathrm{~mm}$ to the plasma plume. on the contrary in the plume of the plasma jet the temperature does'nt vary between 50 and $70 \mathrm{~mm}$.

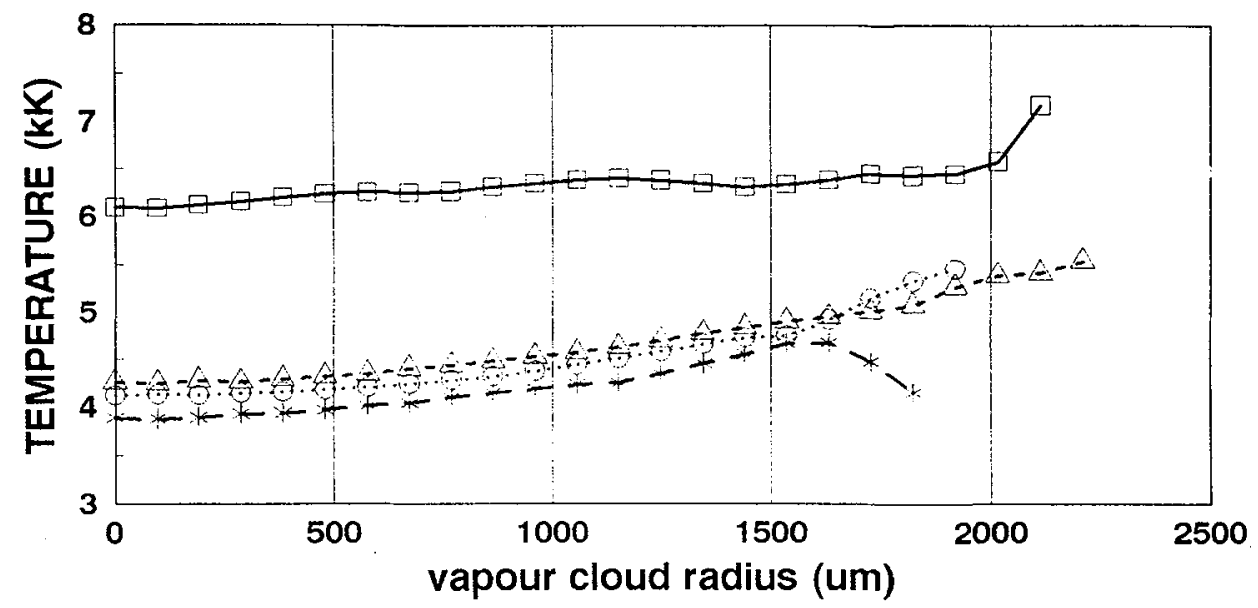

$$
z=40 \mathrm{~mm} \quad z=50 \mathrm{~mm} \quad z=60 \mathrm{~mm} \quad z=70 \mathrm{~mm}
$$

Figure 5: Evolution of the temperature along the vapor cloud radius. 
At least for distances below $70 \mathrm{~mm}$, it seems that the temperature of the vapor increases very fast in the boundary layer close to the particulate (which temperature is below $3000 \mathrm{k}$ ) to reach a mean value either almost constant or with a slowly regular increase up to plasma temperature.

Figures $6 a$ and $b$ show examples of concentration calculated respectively at 40 and $60 \mathrm{~mm}$ from the temperature profiles and the absolute intensity of one of the iron lines. Very high values can be observed: $4.10^{21} \mathrm{~m}^{-3}$ at $40 \mathrm{~mm}$ and $4.10^{23}$ at $60 \mathrm{~mm}$. The radius of the vapor cloud increases with the distance, up to about $60 \mathrm{~mm}$, particulates starting to cool down farther downstream.

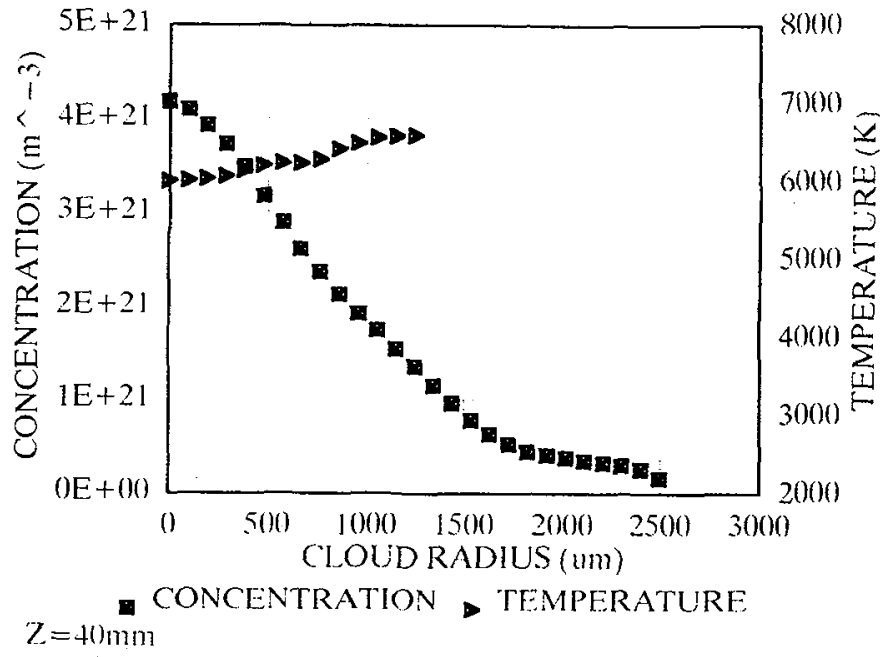

Figure 6a: Concentration and temperature profiles.

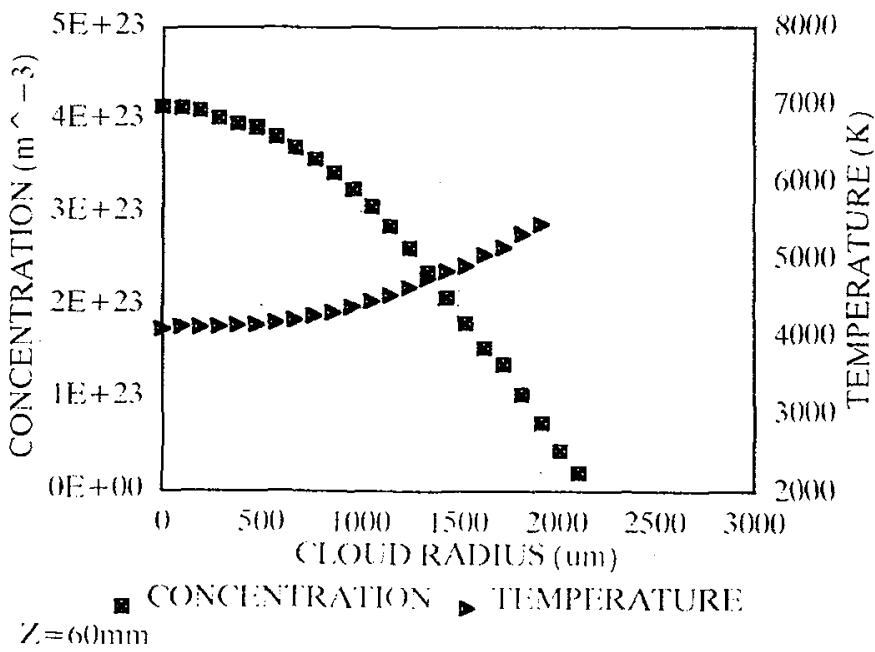

Figure 6b: Concentration and temperature profiles.

Figure 7 shows the concentration distributions in the vapor cloud for particulates at different distances from the nozzle exit. When comparing these values to those obtained by absorption spectroscopy (see fig.3) it is clear that the concentrations around one particulate in flight are higher than the mean values obtained by absorption. It can be explained when 
considering the particulate flowrate (about $2.5 .10^{5}$ part/sec) which are dilated in a plasma volume of $201 / \mathrm{s}$. Assuming an uniform distribution of the particulates the mean distance between two following particulates is about $40 \mathrm{~mm}$. The integration of the obtained concentration at $z=60 \mathrm{~mm}$ over $40 \mathrm{~mm}$ distance gives a mean density of iron atoms of $10^{22} \mathrm{~m}^{-3}$ closer to the absorption measurements represented in figure 3 .

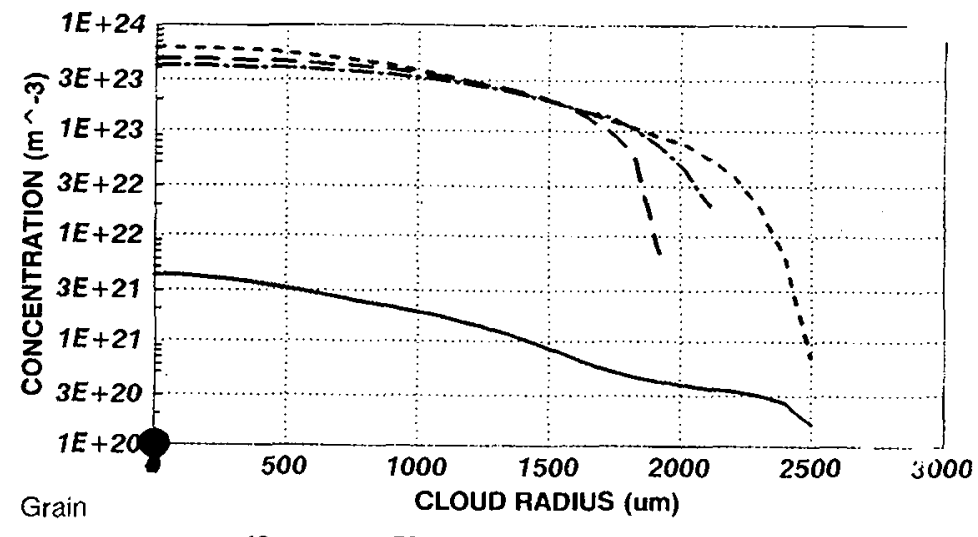

$$
z=40 \mathrm{~mm} \quad z=50 \mathrm{~mm} \quad z=60 \mathrm{~mm} \quad z=70 \mathrm{~mm}
$$

Figure 7: Concentration distribution in the vapor cloud

\section{IV - NUMERICAL STUDY OF THE EVAPORATION OF A SINGLE RARTICULATE}

parallel to the experimental investigation presented in this paper, a numerical simulation of the evaporation of a single particulate has been made.

The intent of this work is to study the influence of the mass transfer on heat transfer coefficient.

In a first step evaporation of a single isolated particulate in an infinite stagnant gas has been studied.

A spherical particulate, initially at temperature $T^{\circ}$ and radius $R^{\circ}$ is suddenly subjected to surrounding gas at uniform temperature $T$. The only convective motion considered is that induced by the evaporation process itself, giving rise to a radial convective velocity in the vapor and gas mixture. Additional assumptions include:

- no second order diffusion effects,

- thermodynamic equilibrium at the interface,

- no pressure variation by evaporation process.

In the particulate, the effects of the temperature gradients and the variation of thermodynamic properties with temperature are taken into account. The transport and thermodynamic properties of the mixture of gas and vapor are calculated from properties of pure gases weighted by mass fraction.

The energy conservation equation in the solid or liquid phase and the energy, mass and species conservation equations in the vapor phase are numerically integrated using finite volume method $/ 8 /$.

Equations in the solid phase are similar to the ones described by Yoshida et al /9/ who have studied the heating of an iron particulate in a R.F.plasma. The temperature profiles for an iron particulate (40 $\mu m$ in diameter) immersed in an argon plasma at 5000 and $7500 \mathrm{~K}$ are shown in Figure 8 ; in both cases the wali temperature of the particulate is about $3000 \mathrm{k}$.

The evaporative flux increases from 19.7 to $35.5 \mathrm{~kg} / \mathrm{m}^{2} \cdot \mathrm{s}$ when the temperature of the gas increases from 5500 to $7500 \mathrm{~K}$.

The nomalized vapor mass fraction for the second case ( $T=7500 \mathrm{~K}$ ) is given in figure 9 .

In the present study, conditions of numerical experiments are different from the experimental ones: computations have been made for pure argon gas and the the convection effect on particulate vaporization has not been taken into account, that explains the poor agreement for the evolution of iron vapor around the particulate; the iron vapor diffusion is also enhanced by the plasma jet fluctuations. Moreover, the particulate size is not really known for experimental results. 




Figure 8: Temperature profiles for 2 different temperatures of plasma gas.



Figure 9:normalized mass fraction of iron vapor.

\section{V - CONCLUSION}

An experimental set up has been developed to investigate the vaporization of a single particulate in flight in a dc plasma jet. It enables to determine the evolution of the temperature and the vapor concentration within the vapor cloud surrounding an evaporating particulate.

Experiments carried out on iron particulates whose diameters range from 22 to $44 \mu \mathrm{m}$ injected in an argon-hydrogen dc plasma jet at the nozzle exit are presented. They show, that the temperature within the diffusion zone is almost uniform close to that of plasma flow, and the thickness of the diffusion zone may be higher than ten times the particulates radii.

A numerical study of a particle vaporization has been made from classical theory of droplet vaporization in a spherically-symmetric stagnant gas at uniform temperature. A better agreement with experimental results, especially for vapor concentration evolution in the diffusion zone, would be obtained by taking into account convection effect on particle vaporization. 


\section{REFERENCES}

/1/ R.W. Smith, D.Wei and D.Apelian, Plasma Chemistry and Plasma Processing, 9, 1, (1989) 1355.

/2/ M. Vardelle, Thèse de Doctorat ès Sciences Physiques, University of Limoges, July (1987), nb 28-87.

/3/ M. Vardelle, C. Trassy, A. Vardelle and P. Fauchais to be published in Plasma Chemistry and Plasma Processing, 11 (1990).

/4/ P. Roumilhac, M. Vardelle, A. Vardelle, P. Fauchais, in Thermal Spray Technology p.111 (pub.) ASM international (1989).

/5/ J.R. Fuhr, C.A. Martin and W.L. Wiese, J. Phys. Chem. Ref. Data, 17, (1988), suppl. 4 .

/6/ C. Trassy, S. Chomet and M. Vardelle, Congrès Européen sur le génie des procédés plasmas thermiques, odeillo, (1990).

/7/ R. Rompe and M. steenbeck, Progress in plasmas and gas electronics, edited by Akademie-Verlag-Berlin, 1 , (1975).

/8/ S.V. Patankar, "Numerical heat transfer and fluid flow" Hemisphere Publishing Corporation, McGraw-Hill, Book Company, New-York.

/9/T.Yoshida,K.Akashi Journal of Physics, 48, (1977), 2252

\section{ACKNOLEDGEMENT}

This work has been supported by CNRS-PIRSEM (ARC "Réacteur plasma en phase héterogène") . 